\title{
OX-2 Membrane Glycoprotein
}

National Cancer Institute

\section{Source}

National Cancer Institute. OX-2 Membrane Glycoprotein. NCI Thesaurus. Code C80109.

OX-2 membrane glycoprotein (278 aa, $\sim 31 \mathrm{kDa}$ ) is encoded by the human CD200 gene.

This protein may play a role in the mediation of both activity and proliferation of myeloid lineage cells. 